\title{
Antropojenik Faaliyetler Nedeniyle Değişen Çevrenin Yarasalar Üzerine Etkileri
}

\author{
Atilla ARSLAN ${ }^{*}$ Mesut BAŞ ${ }^{2}$ \\ ${ }^{1}$ Selçuk Üniversitesi, Fen Fakültesi, Biyoloji Bölümü, Konya, Türkiye \\ ${ }^{2}$ Selçuk Üniversitesi, Fen Bilimleri Enstitüsü, Konya, Türkiye \\ (ORCID: 0000-0002-4766-4969), (ORCID: 0000-0001-5380-3366)
}

\begin{abstract}
Öz
Ekosistemin en önemli dinamiklerinden olan yarasalar, birçok bulaşıcı hastalığın kaynağını oluşturan ve ayrıca tarım için zararlı etkileri olan böcek populasyonunun kontrolünü sağlar. Günümüzde küresel ekosistemin insanlar tarafından değiştirilmesi nedeniyle birçok bilim adamının hemfikir olduğu yeni bir jeolojik çağın -Antroposen Çağ1- başlangıcı tetiklenmektedir. Birçok canlı antropojenik faaliyetleri tolere edip insanlarında içinde bulundukları habitatlarda hayatlarını sürdürmeye devam ederken, canlıların büyük çoğunluğu da dramatik bir şekilde popülasyonlarında düşüş yaşamaktadır. Tüm bu olanların sonucunda da gezegenimiz altıncı büyük yokoluşa doğru itilmektedir. Yarasalar, yaşam döngüleri, beslenme şekilleri, habiatatları, düşük üreme hızı ve yüksek metabolik hızları nedeniyle antropojenik değişikliklere özellikle açıktırlar. Yarasaların \%16'sının IUCN tarafından Kritik Olarak Tehlikeli, Nesli Tehlikede ve Hassas konumda oldukları belirtilmiştir. Bu çalışmada antropojenik faaliyetlerin yarasalar üzerinde nasıl bir etki oluşturduğu vurgulanmıştır. Amacımız, bizim de nokturnal olmaları nedeniyle pek de farkında olmadığımız yarasalar hakkında farkındalık oluşmasını sağlamaktır.
\end{abstract}

Anahtar kelimeler: Ekoloji, ekosistem, korunma statüsü, yarasa.

\section{The Effects of the Changing Environment due to Anthropogenic Activities on Bats}

\section{Abstract}

Bats, one of the most important dynamics of the ecosystem, provide control of the insect population, which is the source of many infectious diseases and also has harmful effects for agriculture. Today, due to the change of the global ecosystem by humans, the beginning of a new geological age - the Antropocene Age - which many scientists agree on is triggering. While many individuals tolerate anthropogenic activities and continue to live in their habitats, the vast majority of individuals experience a dramatic decline in their populations. As a result of all this, our planet is being pushed towards the sixth big extinction. Bats are particularly susceptible to anthropogenic changes due to their life cycle, feeding patterns, habiatates, low reproduction rate and high metabolic rate. $16 \%$ of the bats are reported to be Critically Endangered, Endangered and Vulnerable by IUCN. In this study, it is emphasized how anthropogenic activities have an effect on bats. Our aim is to raise awareness about bats that we are not aware of because they are nocturnal.
\end{abstract}

Keywords: Ecology, ecosystem, protection status, bat.

\section{Giriş}

Yaşadığımız dünya kırılgan olup, insanlar, giderek artan şekildeki yaptıkları faaliyetlerin sonucu oluşan antropojenik etkilerin ekosistem tarafından absorbe edilecekmiş gibi davranır. Dünyanın her yerinden gelen birbirine benzer ve çok kuvvetli kanıtlar, insanoğlunun gezegenimizi değiştirmeye devam ettiğini göstermektedir [1]. İnsanoğlu dünya üzerinde birçok değişime neden olmuştur. Bunlar arasında küresel iklim değişikliğinin ve okyanus asitleşmesinin ana itici gücü olan karbonun atmosfere sanayi devrimiyle

*Sorumlu yazar: aarslan@selcuk.edu.tr

Geliş Tarihi: 14.02.2020, Kabul Tarihi: 28.04.2020 
birlikte 550 milyon tondan fazla salınması [2, 3], yapay gübrelerin kullanımı ile küresel azot döngüsünün değişmesi [4], küresel birincil üretimin üçte birinden fazlasının insan tüketimine yönlendirilmesi [5], türlerin devam eden kitlesel yok oluşları [6] ve istilacı türlerin ve patojenlerin yayılmasına neden olan ticari taşımanın küreselleşmesi [7] en önemlileri olarak görülmektedir. İnsanlığın Dünya'nın jeolojik koşulları ve süreçleri üzerindeki kalıcı etkileri karşısında, 2000 yılında Paul Crutzen ve Eugene Stoermer'den başlayarak birçok bilim adamı, şimdiki eylemlerimizin bizi yeni bir jeolojik çağın başlangıcına (Antroposen Çağı) getirdiğini varsaymaktadır [1]. İnsanlar neredeyse tüm küresel ekosistemleri etkilemekte ve yarasalar bu değişikliklere uyum sağlamaya çalışmaktadır. Bu değişimlerden etkilenen önemli sayıda yarasa göç etmekte, populasyonları azalmakta veya nesli tükenmektedir.

\section{Yarasaların Ekosistemdeki Rolleri}

Böcek ile beslenen yarasalar bazı böcek popülasyonlarını kontrol altında tutarak ekosistemde temel bir rol oynamaktadır. Bazı yarasa türleri, özellikle hayvanlarda ve insanlarda şiddetli hastalıkların etkenlerini bulaştırdıkları bilinen sivrisineklerle beslenmektedir [8]. Yarasalar, tarım ve orman için çok pahalıya mal olan zararlılar arasında yer alan birçok böcek de dahil olmak üzere, uçan çok sayıda böceğin birincil avcılarıdır. Bu yarasaların tükettiği böceklerin kısmen bir listesi, salatalık, patates ve tütün böcekleri; mısır kurdu, koçan kurdu, fidekesen ve buğday güvesi; yaprak zararlıları ve sivrisinekleri içerir. Michigan Millie Hill madeninde kış uykusuna yatan küçük kahverengi yarasa (Myotis lucifugus) sadece bir saat içinde 1.200 sivrisinek boyutunda böcek yakalar. Yarasalar, sivrisinekleri doğal olarak avlayan birkaç hayvan grubundan sadece bir tanesidir [9]. 30.000 Myotis austroriparius'dan oluşan bir Florida kolonisi 15 tonun üzerinde sivrisinek de dahil olmak üzere yılda 50 ton böcek tüketir [10]. Laktasyon dönemindeki bir dişi Brezilya Serbest Kuyruklu Yarasası (Tadarida brasiliensis) her gece vücut kütlesinin \%70 'ine kadar böcek tüketmekte [11], 12 g ağırlığındaki bu yarasadan oluşan doğum kolonisinin tek bir gecede 8.4 tona kadar böcek yiyebileceğini göstermektedir [12]. Böcekçil yarasalarının böcek popülasyonlarını azaltarak ABD tarım endüstrisine olan katkısı 23 milyar \$ / y1l olarak tahmin edilmektedir [13].

Dünya genelinde en az 289 bitki türü (ör. Afrika Baobab ağacı ve Avustralya Demir ağacı) uçan tilkiler (Pteropus sp.) diye bilinen yarasalar tarafından yayılmaya bağımlıdır [14]. Yarasalar bitkilerin döllenmesinin yanında bitki tohumlarının yeni alanlara yayılması ve taşınmasında önemli rol oynarlar. Microchiroptera alt ordosundaki yarasaların birçoğu, uçan tilkiler gibi, guava, avokado, mango, agav, muz vb. gibi birçok bitki türü için nakilci ve tozlayıcı olarak hareket ederler [14, 15].

Besin maddesi dağılımı ve toprak verimliliği için, yarasa guanosu, mükemmel bir ekolojik potansiyele sahiptir. Böylece, yarasalar besin açısından zengin bölgelerden (örn. Göl ve nehirler) daha fakir bölgelere (örneğin, kurak veya dağlık alan) besin öğelerinin yeniden dağıtılmasına katkıda bulunurlar [16].

\section{Antropojenik Faaliyetler Ve Yarasalar Üzerine Etkileri}

\section{1. Çevre kirliliğ i}

Yarasa popülasyonunun azalması, çevre ve iklim değişikliği, kaynaklardaki değişiklikler, av durumu ve kalitesi, tünek kaybı, rahatsızlık, şehirleşme ve sanayileşme, tarımsal yoğunlaşma, rüzgâr türbinlerinde artış, hastalık baskısı ve çevredeki kimyasallara maruz kalma [17-20] gibi bir dizi faktörün sonucu olabilir. Son yıllarda, Avrupa'da ve Kuzey Amerika'daki yarasa popülasyonlarında düşüşler (örn. Pipistrellus sp., Rhinolophus hipposideros, Rhinolophus ferrumequinum ve Myotis myotis gibi türler dahil olmak üzere) gözlenmiştir [21-23]. Nispeten uzun ömürleri (örneğin 40 yaşına kadar) ve günlük yüksek gıda alımı nedeniyle $[24,25]$ yarasalar, özellikle gıda zincirinde biriken metaller gibi kimyasal kirleticilere maruz kalma eğilimi gösterebilir [26]. Temel maruz kalma yolları, kirlenmiş gıda ve suyun kullanılması, dermal maruz kalma ve inhalasyon şeklindedir [27, 28].

Su kaynaklarının az olduğu kurak alanlarda, su kaynağına yönelik herhangi bir kayıp veya bozulma, ona bağlı olan yaban hayatı için zararlı olabilecek etkiler yaratabilir. Yarasalar kirli bir kaynaktan su içtiğinde, toksinleri direkt olarak alırken avlanma sırasında böceklerin bünyesinde biyolojik birikim yapmış toksinleri dolaylı yoldan alırlar. Örneğin, böcek larvaları kimyasal olarak kirli 
suda beslendiyse, kirleticileri vücutlarına biriktirirler ve metamorfoz sonucu yetişkin olan böcekler yarasalar tarafindan tüketilirler [29]. Sucul habitatlarda beslenen yarasalar, beslendikleri böceklerde biyolojik olarak büyük oranda birikmiş toksik ağır metallere maruz kaldıkları bilinmektedir [30]. Kanalizasyon arıtma tesislerinde kanalizasyon çamurunda ve atık suda oluşan uçucu böceklerin, endokrin sistemini bozabilecek kirleticiler biriktirebileceğine dair kanttlar bulunmuştur [31].

\subsection{Madencilik}

Madencilik, çevresel yıkım ve kirliliğin global olarak büyük bir antropojenik kaynağıdır. 1980 ve 1989 yılları arasında Kaliforniya, Nevada ve Arizona'da altın madenciliği için kullanılan siyanürlü havuzlarda öldüğü bilinen memelilerin \%34'ünü yarasalar oluşturmaktadır [32]. Ölü yarasalarda arsenik, kadmiyum, krom, bakır, kurşun, civa, metil civa, nikel ve çinko gibi madencilik işlemlerinde kullanılan diğer ağır metaller bulunmuştur [29]. ABD'de, Arizona'da büyük bir bakır eritme madeninden $8 \mathrm{~km}$ uzakta yaşayan Tadarida brasiliensis dokularında önemli miktarda atmosferik civa birikimi tespit edilmiştir [33].

\subsection{Karayolları}

Yollar habitatı küçültür, tahrip eder ve doğal manzarayı bozarlar [34]. Ayrıca yarasaları, araçlarla çarpışma sonucu ölüm, avlanma alanlarını küçültmek veya zarar vermek ve gidiş-geliş ile göç için kullanılan kritik uçuş rotalarını değiştirmek gibi farklı yollardan da etkiler [35].

Yol yapımı, çoğunlukla mevcut veya olması muhtemel yarasa tüneklerini barındıran ağaçların ve binaların ortadan kaldırılmasına yol açar. Ağaçların, çalıların, sulak alanlar ve işlenmemiş (doğal) çayırların ortadan kaldırılması aynı zamanda mevcut habitat alanını da azaltır. Yol yüzeyi tek başına, 7 m genişliğindeki her 10 km'lik iki şeritli yol için 7 hektara kadar önemli habitat alanının kaybına neden olur. Yol kenarlarında banketler, köşeler, kavşaklar, servis alanları ve diğer yapılar daha fazla potansiyel bir habitatı ortadan kaldırır. Sonuç olarak, yol yapımı yarasa için habitatların kalıcı olarak yok olmasına ve dolayısıyla doğrudan popülasyon boyutlarının azalmasına neden olmaktadır [36]. Kerth and Melber [37] Almanya'daki önemli bir karayolunun, dişi Myotis bechsteinii'nin yaşam alanlarına erişimini kısıtladığını, daha küçük avlanma alanlarına ve düşük üreme başarısına neden olduğunu tespit etmiştir.

Karayolları tünekler ile avlanma bölgeleri arasındaki uçuşlarda potansiyel bariyerlerdir. $\mathrm{Bu}$ nedenle kullanışlı tünek ile avlanma mesafe aralığı artabilir ve avlanma bölgesinin kalitesi düşebilir. Bu durum göçü kısıtlayarak ölüm oranını artırabilir ve üreme potansiyelini azaltabilir. Yollar, ulaşılabilir alanı ve kalitesini düşürerek habitat parçalanmasına neden olabilir. Habitat alanı ve kalitesi popülasyon büyüklüğ̈nün belirleyici unsurları olduğundan, habitat parçalanması sürdürülebilir popülasyon boyutunu düşürebilmektedir. Yollar gibi bariyerler, bireylerin popülasyonlar arasındaki dolaşımını iki önemli sonuçla sinırlayabilir. Birincisi, bariyerler komşu popülasyondan bireylerin takviyesini [kurtarma etkisini] azaltacağından dolayı yerel popülasyondaki düşüşün iyileşmesini yavaşlatabilir ve bu da yerel anlamda soyun tükenmesi olasılığını daha da artıracaktır. İkincisi, bariyerler ayrıca popülasyonlar arasındaki gen akışını azaltabilir ve akrabalık derecesini artırarak bireysel uygunluğu azaltabilir. Bunun neticesinde yerel yok olma riski artabilmektedir [36].

Yarasaların yollardan karşıdan karşıya geçmeye teşebbüs etmesi araçlarla çarpışma riskini taşır ve mortalite için sıcak bölgeler oluşturur [38-40]. Uçmada çevik ve manevra kabiliyeti olmasına rağmen, çoğu yarasa türü düşük hızda $(<20 \mathrm{~km} / \mathrm{s})$ uçar ve özellikle açık alanları geçerken yere yakın uçarlar $(0-$ $4 \mathrm{~m})[40,41]$. Bu nitelikler, hareket halindeki araçlara karşı yol boyunca beslenen ya da yolları geçmeye çalışan yarasaları çok savunmasız duruma getirir. Küçük olmaları nedeniyle yarasalar, geçmekte olan araçların oluşturduğu hava akımı içine kolayca çekilebilir [36]. Yapılan bir çalışmada, dört yaz dönemi boyunca iki şeritli bir karayolunun $8 \mathrm{~km}$ 'lik kesiminde karkas araması yapılarak ölü yarasalar kaydedilmiştir. $\mathrm{Bu}$ çalışma sonucunda, bulunan karkas sayısı yerleşim alanlarında 0,3 yarasa/km/yıl, ağaçlarla çevrilmiş yollarda 6,8 yarasa/km/yıl olduğu tespit edilmiştir [38].

\subsection{Habitat bozulması}

Birçok çalışma yol aydınlatmasının yavaş uçan ve ormanlık alanlara adapte olmuş Rhinolophus, Myotis ve Plecotus cinslerine ait birçok türün yola yaklaşmasını önlediğini göstermektedir [23, 42, 43]. 
Aydınlatma, muhtemelen yolların bariyer etkisini artırır, çünkü açık alanlardan geçme konusunda isteksiz olan bu türlerin ışıktan kaçınma ihtimalini artırır. Hem yüksek basınçlı sodyum hem de beyaz LED ışığı, düşük yoğunlukta bile ormana adapte olmuş türleri caydırmaktadır [23]. Günlük aktivitelerde 1şığın neden olduğu değişiklikler, hem tür içinde (ör. çiftleşme için) hem de türler arasındaki rekabeti değiştirebilir [44]. Suni ş̧ık, diurnal türlerin aktivitesini uzatarak niş ayrışmasını etkileyebilir ve onları nokturnal türler ile türlerarası rekabete sokabilir [45]. Örneğin, makas kuyruklu sinekkapan olarak adlandırılan Tyrannus forficatus, gün batımından sonra en az 3 saat boyunca sokak 1şıklarında böcekleri yakalar [46]. Bu durum böcek ile beslenen yarasalarla rekabeti artırabilir. Işık kirliliği, aydınlatma kaynaklarından faydalanan ışığa toleranslı türler hariç olmak üzere ışığa hassas yarasa türleri arasında rekabete de neden olabilir [47]. Yapay ışık, yarasalar için uygun olmayan ulaşım yollarını ve yiyecek arama alanlarını kullanmaya neden olur. Yapay ışı düzeyleri, 'yapay ay fobisi' veya sirkadiyen bir uyuşmazlık nedeniyle yarasaların avlanma verimliliğini düşürür. Bunun sonucunda ortaya çıkan enerji harcamasındaki artış ve azalan enerji kazanc1; azalmış dirence, form düşüşüne ve nihayetinde popülasyon düşüşlerine neden olabilir [1].

Böcekçil yarasaların çoğu, avını tespit etmek, yönlerini bulmak ve hatta iletişism kurmak için ultrasonik ekolokasyon çağrılarını kullanırlar. Bazı türler, kanat hareketleri veya çiftleşme çağrısı gibi avları tarafindan üretilen sesleri dinleyerek avlarını bulur ve yakalarlar. Trafik gürültüsü avın ürettiği sesleri ve ekolokasyon çağrılarının daha düşük frekans bileşenlerini maskeleyebilir. Kapalı uçuş odası deneyleri sırasında simüle edilmiş trafik gürültüsü, tipik olarak zeminde bulunan avı tarafından çıkarılan sesleri dinleyerek avlanan Myotis myotis'in besleme etkinliğini azalttı̆̆ı tespit edilmiştir [48]. Muhtemelen gürültülü yollara yakın habitatlar, toprakta veya bitki örtüsünde bulunan avların seslerini dinleyerek avlanan bu ve diğer türler için beslenme alanları olarak seçilmemesi muhtemeldir. Araç gürültüsü de bariyer etkisini artırabilir [49]. Karayolu inşaat gürültüsü (ör. Ağır teçhizat, patlatma ve kazık çakma gibi), özellikle köprüler, menfezler veya diğer karayolu altyapısında ya da yakınlardaki binalarda, ağaçlarda ya da kaya çıkıntılarında tüneyen yarasaları etkileyebilir. Yüksek sesler yarasaları rahatsız edebilir ve tüneklerin terk edilmesine neden olabilir [50-53]. Eğer gürültü yeterince yüksek ve ani olursa, yarasalarda geçici veya sürekli işitme kaybına neden olabilir. Kronik rahatsızlık, özellikle üreme mevsiminde, önemli koloni aktivite şekillerini değiştirebilir [54, 55], kış uykusuna yatan ve kışlayan yarasaların kritik torpor döngülerini bozarak kritik enerji kaynaklarını aşırı kullanmaya zorlayabilir [50, 56, 57].

\subsection{Rüzgâr enerji santralleri}

Rüzgâr enerjisi, konvansiyonel enerji kaynakları içinde dünya genelinde en hılı büyüyen yenilenebilir enerji kaynaklarından biridir [58]. Rüzgâr enerjisinin yaban hayatı ve habitatları üzerindeki etkileri belgelenmiş olup artan bir endişe kaynağı haline gelmiştir [59].

Rüzgâr enerjisinin gelişimi, yaban hayatını doğrudan mortalite ve dolaylı olarak da habitat yapıs1 ve fonksiyonu üzerine etki eder [60-62]. 1972 yılından beri rüzgâr enerji sistemlerinde kuş ve yarasa ölümleri ile ilgili çalışmalar yapılmaktadır [63]. Yarasalarla ilgili Avrupa ve Kuzey Amerika'da yapılan çalışmalarda rüzgâr türbinlerinin kanatlarına doğrudan çarparak veya dolaylı olarak ölümlerin olduğu tespit edilmiştir [64, 65]. 2005 yılında yapılan bir çalışmada, Pennsylvania ve Batı Virginia'da 64 rüzgâr türbininde 6 haftalık araştırma ve gözlem sonucunda 13 türe ait toplam 660 yarasanın öldügüne dair tespitte bulunulmuştur [64]. 2008 yılında İtalya'da yapılan bir çalışmada iki farklı bölgede toplam 46 türbinde iki farklı türe ait 7 yarasa ölüsü tespit edilmiştir [66]. Kanada ve Amerika'da yapılan başka bir çalışmada rüzgâr türbinlerinin kanat hızının yarasalar üzerine olan etkisi araştırılmış ve 6 $\mathrm{m} / \mathrm{s}$ 'nin üzerindeki hızlarda yarasa ölümlerinin $\% 85$ oranında azaldığı görülmüştür [67]. Yarasaların rüzgâr türbinlerinden daha çok ağustos-eylül ayları arasında etkilendiği ve yarasa ölümlerinin bu aylarda daha fazla olduğu araştırmalar sonucunda ortaya konmuştur. Bahar aylarında ise bu etkinin daha düşük olduğu tespit edilmiştir [64, 66, 68, 69]. Rüzgar türbin bıçaklarının etrafindaki ani hava basıncı düşüşü, yarasaların akciğerlerini patlattığı kanıtlanmış ve bu durum "baro-travma" sendromu olarak literatüre geçmiştir [70]. 


\subsection{Mağara turizmi}

19. yüzyılın sonlarında başlayan mağara turizmi, mağaralardaki tüm canlılar için önemli ölçüde tehdit oluşturmaktadır. 1990'ların ortalarında dünya genelinde yaklaşık 20 milyon kişinin her yıl eğlenmek amacıyla mağaraları ziyaret ettiği tahmin edilmektedir [71-74]. Turizme yönelik mağaraların geliştirilmesi tipik olarak suni aydınlatma, merdivenler, yürüyüş yolları, otoparklar şeklinde mağara ortamlarında fiziksel değişiklikler oluşturan giriş yapıları içerir (Şekil 1). Mağara ziyaretçilerinin varlığından kaynaklanan rahatsızlığın yanı sıra sıcaklık, nispi nem ve karbondioksit konsantrasyonları üzerinde belirgin bir dalgalanma yaratmakta ve bunların hepsi yarasalar için tünekten vazgeçmeye neden olabilmektedir. Örneğin Kanada'nın Quebec'teki Bonnechere Mağarası'nın ticarileştirilmesi, Myotis leibii'nin Kuzey Amerika'daki en büyük kış uykusu barınağından vazgeçmesine neden olmuştur [75].

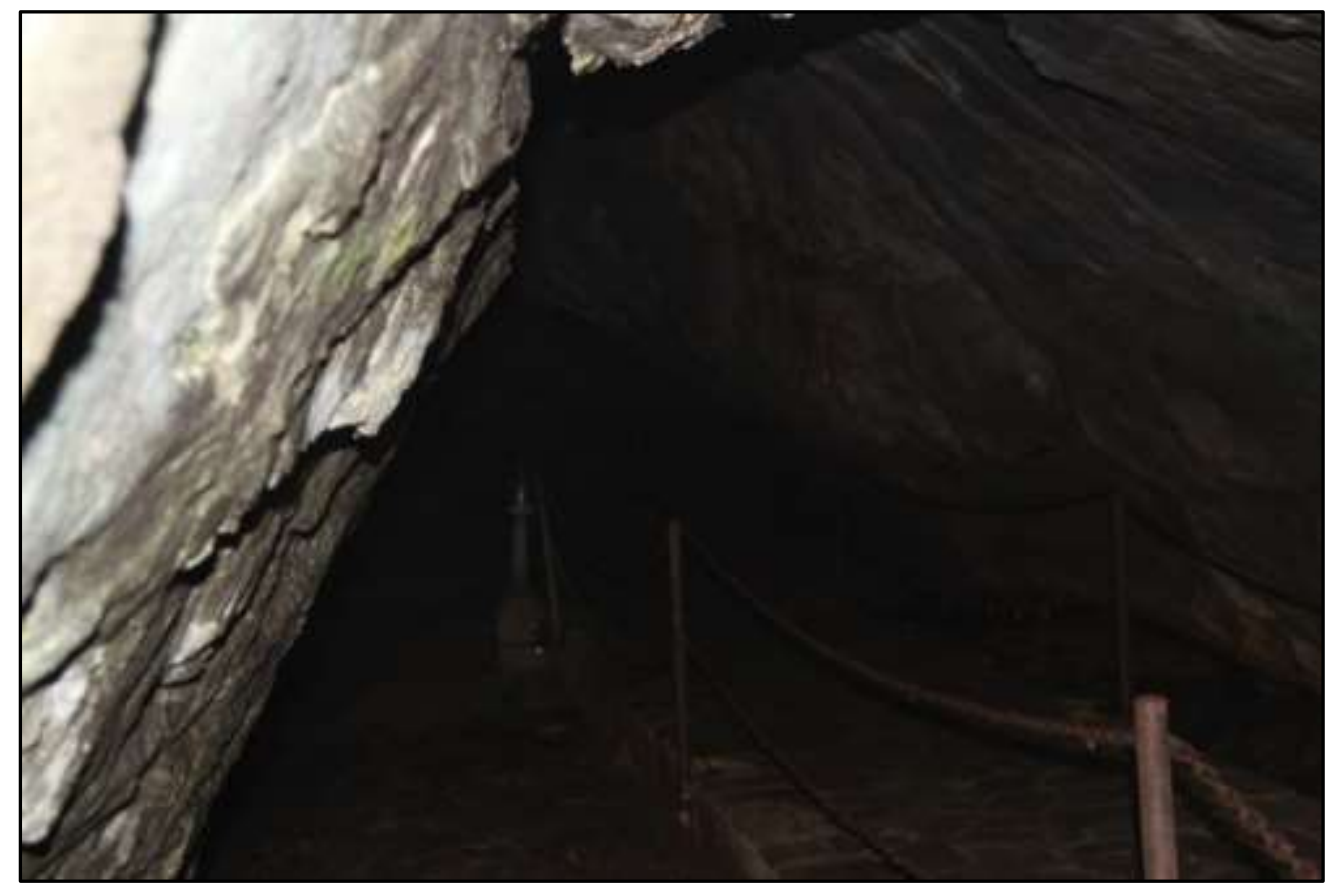

Şekil 1. Turizme açılmış Kırklareli Dupnisa Mağarası

Mann ve ark. [54], 1000 Myotis velifer'den oluşan bir doğum kolonisinin deneysel olarak mağara turlarına maruz bırakılarak davranışsal tepkilerini araştırmıştır. Yüksek 1şık yoğunluğu, tur rotalarının yakınlığı ve tur gruplarının konuşmaları, yarasa aktivite seviyeleri ve uçuş artışı ile olumsuz bir etkiye sahip olduğu ve doğum sezonu ilerledikçe, tüm bu davranış tepkilerinin arttığını tespit etmişlerdir. Luo ve ark. [73]'nın Çin'deki 225 yeraltı bölgesinde yaptığı bir çalışmada, rekreasyon faaliyetlerinin yarasa sayıları ve risk altındaki türlerin varlığı üzerinde olumsuz etkilere neden olduğunu göstermiştir. Turizmin yarasa sayılarına etkilerini inceleyen az sayıdaki ayrıntılı araştırmalardan biri de, Güneydoğu Avrupa'daki yarasaların en büyük kolonilerinden biri olan Trakya Bölgesi'ndeki Dupnisa Mağara Sistemi'nde yapılmıştır. Bu mağara sisteminde, 15 tür içeren ortalama kışın 25.000 ve yaz aylarında 4000 yarasa bulunmaktadır. Üç mağaradan oluşan Dupnisa Mağarası'nda tek bir ölçümde kaydedilen azami yarasa sayıs1 56.000'dir [76]. Furman ve ark. [77]'nın bu mağarada Mart 2001'de yaptıkları araştırma ile karşılaş̧ırıldığında Şubat ve Mart 2003-08 döneminde iki hibernasyon mağarasında sırasıyla \%20 ve \%60'lık bir azalma olduğunu, Nisan 2001'deki araştırmaya kıyasla Nisan ve Mayıs 2002- 07'de doğum mağarasında \%90'lık bir azalma olduğu sonucuna varmışlardır [78].

\subsection{Yarasa guanosu ticareti}

Yarasalar avladıkları sinek ve diğer böceklerin yaklaşı \%15-20'sini sindirebilmekte, kalan kısmı dışkıyla atılmaktadır. Bundan dolayı yarasa gübresi azot, magnezyum, fosfor, demir, potasyum, mangan ve çinko yönünden oldukça zengindir [79]. Yarasa guanosunun öneminin artmasiyla birlikte, mağaralardan guano çıkarılması çeşitli sorunların ortaya çıkmasına da neden olmuştur. 
Mağara ekosistemlerinde birincil enerji kaynağı olarak yarasa guanosu kullanılmaktadır. Mağaralardaki karasal omurgasız faunanın hayatta kalması guanoya bağlıdır [80]. Yarasaların düşük üreme hızına sahip olması nedeniyle popülasyonlarının antropojenik faaliyetlerle ilişkili kayıplarından kurtulması uzun zaman almaktadır [81]. Bu durum, mağara yarasaları için önemli bir sorun oluşturmaktadır, çünkü nispeten küçük ve sınırlı alanlara sahip olan mağaraların ekosistemlerinin herhangi bir şekilde bozulması tüm kolonileri etkileyebilmektedir. Mağaralardan guanonun çıkartılması, üreme mevsiminin başlarında özellikle dişi yarasaların tüneklerini terk etmelerine neden olabilir. Bu durum, dişilerin üremek için yeterli şartları sağlamayan tüneklere göç etmelerine neden olarak onların üreme başarılarını azaltabilir. Ayrıca bu durum yarasalarda rahatsızlık oluşturarak, tüneklerdeki yarasaların genel aktivite seviyesini yükseltebilir, daha fazla enerji harcanmasına ve emziren dişilerin yavrularını daha az verimli beslemesine neden olabilir. Bunun sonucunda dişi yarasaların yavrularını besleyebilmek için avlanma talepleri artabilir. Ayrıca doğum kolonilerinin rahatsız edilmesi, mağara tabanına düşen gençlerin doğrudan ölümüne de neden olabilir [82, 83].

\subsection{Kentsel ortamlar}

Yarasalar kentsel alanlarda kalan en çeşitli memeliler grubunu oluşturur [84, 85]. Günümüze kadar kentsel peyzajda yapılan araştırmalardan birçoğu, genel yarasa aktivitesinin ve tür zenginliğinin doğal alanlarda en fazla olduğunu ve artan kentsel etkiler ile azaldığını göstermektedir [86-90]. Tüm şehirlerde kentsel ağaç örtüsü büyük ölçüde sabit $(<\% 30)$ olduğu için [91], ağaç yönünden zengin bölgelerdeki kentleşme, ormansızlaşma anlamına gelir ve ağaç örtüsünün azaltılması kentleşmenin olumsuz etkisine neden olabilir. Buna karşılık, mera alanları içerisindeki kentsel alanlar yapısal heterojenliği artırabilir ve böylece tür zenginliğini artırabilir [92].

Kentsel ortamlarda yarasa ile ilgili yapılan çalışmaların çoğu, Avrupa ve Kuzey Amerika'nın 1lıman bölgelerinden gelmektedir. Bu çalışmaların çoğu eski yerleşim alanları, nehir yaşam alanları veya park alanları gibi bitki örtüsüne sahip bölgelerde nispeten yüksek yarasa aktivitesi ve tür zenginliği bildirmektedir. Türe özgü niteliklerle bağlantılı olarak bazı yarasa türleri bu kentsel ortamlarda başarılı gibi gözükmektedir [93].

Jung ve Threlfall [94]'in yapmış olduğu meta-analizde genel olarak, kentsel alanlardaki yarasaların habitat kullanımının azaldığını ortaya koymuştur. Yüksek derecede şehirleşmenin orta dereceli kentsel gelişime kıyasla yarasaların genel yaşam alanı kullanımı üzerinde daha güçlü bir olumsuz etkisi vardır. Bununla birlikte, orta seviyede kentsel gelişmede habitat kullanımı, doğal alanlara kıyasla çok daha düşüktür.

\section{Sonuç ve Öneriler}

Avustralya'ya bağlı bir ada olan Christmas Adası'nda yaşayan Pipistrellus murrayi'ye 2009 yılından sonra rastlanılmamıştır [95-97]. Bu tür büyük olasılıkla gezegenimizden kaybolacak son tür değildir. IUCN tarafindan Desmodus draculae, Pteropus brunneus, $P$. pilosus, $P$. subniger ve $P$. tokudae soyu tükenmiş beş tür olarak değerlendirilmiştir (Şekil 2). Desmodus draculae sadece fosil ve alt fosil kayıtlarından tespit edilmiş ve yok oluş nedeni bilinmemektedir. Bununla birlikte, yok olmuş dört Pteropus türü tümüyle yok olmanın ana itici faktörü olan av ve habitat kaybı ile antropojenik faaliyetlerin kurbanıdır [1].

Azalan popülasyon ve belirlenen tehditler, umutsuz bir gelecek izlenimi uyandırmaktadır. Küresel olarak, IUCN değerlendirmeleriyle tespit edilen yarasa türlerine yönelik en büyük tehditler, arazi kullanımı değişikliği (kerestecilik, kerestesi olmayan ürün yetiştiriciliği, çiftlik hayvancıllğg ve ağaçlandırma, odun ve kâğıt yapımı ve yangın), kentleşme, taş ocakçılığı ve yarasa habitatlarına genel insani müdahalelerdir [1].

Ülkemizde birçok yarasa türünün yaşam alanlarını da oluşturan mağaraların korunması ile ilgili 03.02.2016 tarihinde T.C. Çevre ve Şehircilik Bakanlığ tarafından "Tabiat varlığ 1 olarak belirlenecek olan doğal mağaralara ilişkin ilke kararı" alınmıştır (25 Mart 2016 tarih ve 29664 sayılı Resmi Gazete'de yayımlanmıştır). T.C. Orman ve Su İşleri Bakanlığına bağlı Doğa Koruma ve Milli Parklar Genel Müdürlüğü, mağaralardan guano çıkarmak isteyenlerin uyması gereken kuralları belirlemiş ve taahhütaname hazırlamıştır. T.C. Gıda, Tarım ve Hayvancılık Bakanlığı tarafindan "İnsani tüketim amacıyla kullanılmayan hayvansal yan ürünler yönetmeliği” yayımlanmış (24 Aralık 2011 ve 28152 
sayılı Resmi Gazete) ve bu yönetmeliğe istinaden, yarasalardan elde edilen guanonun piyasaya hangi şartlarda arz edileceği ile ilgili 2017/44 sayılı uygulama tebliği yayımlanmıştır.

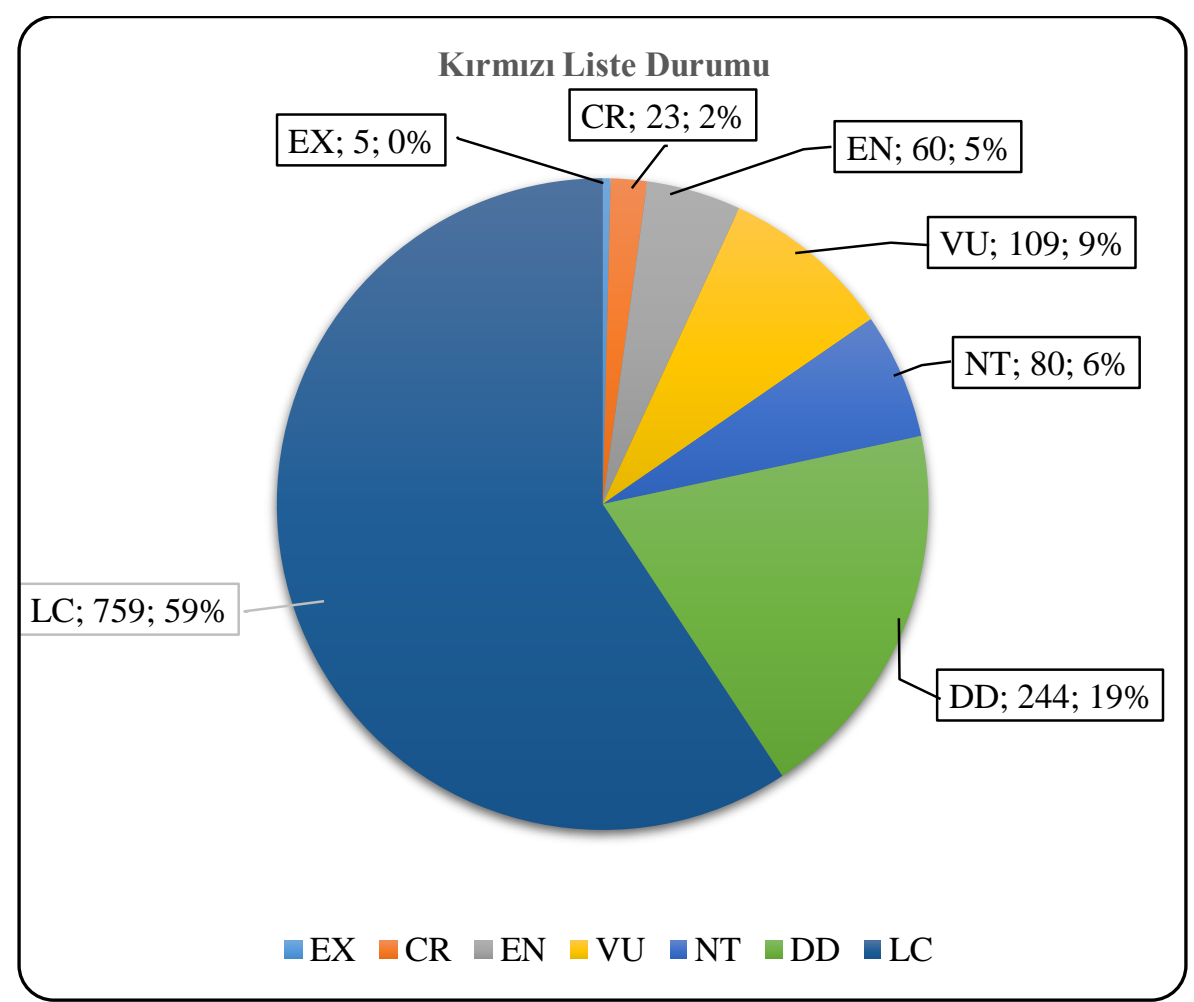

Şekil 2. IUCN tarafından değerlendirilen 1280 yarasa türünün Kırmızı Liste durumu (Kategori; tür sayıs1; yüzdesi) [97]. IUCN kategorileri, Nesli Tükenmiş (EX), Kritik Olarak Tehlikeli (CR), Nesli Tehlikede (EN), Hassas (VU), Tehdit Altında (NT), Yetersiz Veri (DD), Minimum Endişe (LC).

Sonuç olarak, nokturnal hayvanlar olarak yarasalar, insanların neden olduğu ekolojik bozulmalara maruz kalmaktadır. Çünkü koruma planları yapılırken çoğunlukla görünen olaylara odaklanılmakta ve bu nedenle korumanın karanlık tarafı, yani nokturnal hayvanların korunması ihmal edilmektedir.

\section{Yazarların Katkısı}

Atilla ARSLAN konunun belirlenmesi, ilgili kaynakların toplanması ve makalenin yazımına; Mesut BAŞ ise ilgili kaynakların toplanması ve makalenin yazımına katkı sağlamıştır.

\section{Çıkar Çatışması Beyanı}

Yazarlar arasında herhangi bir çıkar çatışması bulunmamaktadır.

\section{Araştırma ve Yayın Etiği Beyanı}

Yapılan çalışmada, araştırma ve yayın etiğine uyulmuştur.

\section{Kaynaklar}

[1] Voigt C.C., Kingston T. 2016. Bats in the Anthropocene: Conservation of Bats in a Changing World. Springer Science+ Business Media, USA.

[2] Ciais P., Sabine C., Bala G., Bopp L., Brovkin V., et al. 2013. The Physical Science Basis. Contribution of Working Group I to The Fifth Assessment Report of The Intergovernmental Panel on Climate Change. IPCC Climate Change, 465-570. 
[3] Gray V. 2007. Climate Change 2007: The Physical Science Basis Summary for Policymakers. Energy \& Environment, 18 (3-4): 433-40.

[4] Canfield D.E., Glazer A.N., Falkowski P.G. 2010. The Evolution and Future of Earth's Nitrogen Cycle. Science, 330 (6001): 192-6.

[5] Krausmann F., Erb K.H., Gingrich S., Haberl H., Bondeau A., Gaube V., Lauk C., Plutzar C., Searchinger T.D. 2013. Global Human Appropriation of Net Primary Production Doubled in the 20th Century. Proceedings of The National Academy of Sciences, 110 (25): 10324-10329.

[6] Barnosky A.D., Matzke N., Tomiya S., Wogan G.O.U., Swartz B., Quental T.B., Marshall C., McGuire J.L., Lindsey E.L., Maguire K.C., Mersey B., Ferrer E.A. 2011. Has the Earth's Sixth Mass Extinction Already Arrived. Nature, 471 (7336): 51.

[7] Lewis S.L., Maslin M.A. 2015. Defining the Anthropocene. Nature, 519 (7542): 171-80.

[8] Mehlhorn H. 2014. Introduction: The World of Bats. Bats (Chiroptera) as Vectors of Diseases and Parasites. Springer, 1-5.

[9] Ducummon S.L. 2000. Ecological and Economic Importance of Bats. Bat Conservation International, Austin, TX.

[10] Zinn T.L., Humphrey S.R. 1981. Seasonal Food Resources and Prey Selection of the Southeastern Brown Bat (Myotis austroriparius) in Florida. Florida Scientist, 81-90.

[11] Kunz T.H., Whitaker J., Wadanoli M. 1995. Dietary Energetics of the Insectivorous Mexican Free-Tailed Bat (Tadarida brasiliensis) During Pregnancy and Lactation. Oecologia, 101 (4): 407-15.

[12] Kasso M., Balakrishnan M. 2013. Ecological and Economic Importance of Bats (Order Chiroptera). ISRN Biodiversity.

[13] Boyles J.G., Cryan P.M., McCracken G.F., Kunz T.H. 2011. Economic Importance of Bats in Agriculture. Science, 332 (6025): 41-2.

[14] Fujita M.S., Tuttle M.D. 1991. Flying Foxes (Chiroptera: Pteropodidae): Threatened Animals of Key Ecological and Economic Importance. Conservation Biology, 5 (4): 455-63.

[15] Hill J., Smith J. 1984. Bats: A Natural History. Journal of Mammology, 121-2.

[16] Buchler E. 1975. Food Transit Time in Myotis lucifugus Chiroptera: Vespertilionidae. Journal of Mammalogy, 56 (1): 252-5.

[17] Frick W.F., Reynolds D.S., Kunz T.H. 2010. Influence of Climate and Reproductive Timing on Demography of Little Brown Myotis Myotis Lucifugus. Journal of Animal Ecology, 79 (1): 12836.

[18] Jones G., Jacobs D.S., Kunz T.H., Willig M.R., Racey P.A. 2009. Carpe Noctem: The Importance of Bats as Bioindicators. Endangered Species Research, 8 (1-2): 93-115.

[19] Walker L., Simpson V., Rockett L., Wienburg C., Shore R. 2007. Heavy Metal Contamination in Bats in Britain. Environmental Pollution, 148 (2): 483-90.

[20] Wickramasinghe L.P., Harris S., Jones G., Vaughan N. 2003. Bat Activity and Species Richness on Organic and Conventional Farms: Impact of Agricultural Intensification. Journal of Applied Ecology, 40 (6): 984-93.

[21] Dietz C., Nill D., von Helversen O. 2009. Bats of Britain, Europe and Northwest Africa. A \& C Black.

[22] Stebbings R.E. 1988. The conservation of European bats. Christopher Helm Pub Limited.

[23] Stone E.L., Jones G., Harris S. 2009. Street Lighting Disturbs Commuting Bats. Current Biology, 19 (13): 1123-7.

[24] Anthony E.L., Kunz T.H. 1977. Feeding Strategies of the Little Brown Bat, Myotis lucifugus, in Southern New Hampshire. Ecology, 58 (4): 775-86.

[25] Podlutsky A.J., Khritankov A.M., Ovodov N.D., Austad S.N. 2005. A New Field Record for Bat Longevity. The Journals of Gerontology Series A: Biological Sciences and Medical Sciences, 60 (11): 1366-8.

[26] Hickey M., Fenton M., MacDonald K., Soulliere C. 2001. Trace Elements in The Fur of Bats (Chiroptera: Vespertilionidae) From Ontario and Quebec, Canada. Bulletin of Environmental Contamination and Toxicology, 66 (6): 699-706.

[27] Allinson G., Mispagel C., Kajiwara N., Anan Y., Hashimoto J., Laurenson L., Allinson M., Tanabe S. 2006. Organochlorine and Trace Metal Residues in Adult Southern Bent-Wing Bat (Miniopterus schreibersii bassanii) in Southeastern Australia. Chemosphere, 64 (9): 1464-71. 
[28] Lilley T.M., Meierjohann A., Ruokolainen L., Peltonen J., Vesterinen E., Kronberg L., Nikinmaa M. 2012. Reed Beds May Facilitate Transfer of Tributyltin From Aquatic to Terrestrial Ecosystems Through Insect Vectors in The Archipelago Sea, SW Finland. Environmental Toxicology and Chemistry, 31 (8): 1781-1787.

[29] Korine C., Adams R., Russo D., Fisher-Phelps M., Jacobs D. 2016. Bats and Water: Anthropogenic Alterations Threaten Global Bat Populations. Bats in The Anthropocene: Conservation of Bats in a Changing World. Springer, Cham, 215-241.

[30] Pikula J., Zukal J., Adam V., Bandouchova H., Beklova M., Hajkova P., Horakova J., Kizek R., Valentikova L. 2010. Heavy Metals and Metallothionein in Vespertilionid Bats Foraging Over Aquatic Habitats in the Czech Republic. Environmental Toxicology and Chemistry: An International Journal, 29 (3): 501-5066.

[31] Park K.J., Müller C.T., Markman S., Swinscow-Hall O., Pascoe D., Buchanan K.L. 2009. Detection of Endocrine Disrupting Chemicals in Aerial Invertebrates at Sewage Treatment Works. Chemosphere, 77 (11): 1459-1464.

[32] Clark Jr.D., Hothem R.L. 1991. Mammal Mortality at Arizona, California, and Nevada Gold Mines Using Cyanide Extraction. California Fish and Game, 77 (2): 61-9.

[33] Petit M.G., Altenbach J.S. 1973. A Chronological Record of Environmental Chemicals From Analysis of Stratified Vertebrate Excretion Deposited in a Sheltered Environment. Environmental Research, 6 (3): 339-43.

[34] Forman R.T.T., Sperling D., Bissonette J.A., Clevenger A.P., Cutshall C.D., Dale V.H., Fahrig L., France R., Goldman C.R., Heanue K., Jones J.A., Swanson F.J., Turrentine T., Winter T.C. 2003. Road ecology: science and solutions. Island Press.

[35] Berthinussen A., Altringham J. 2012. The Effect of a Major Road on Bat Activity and Diversity. Journal of Applied Ecology, 49 (1): 82-89.

[36] Altringham J, Kerth G. 2016. Bats and roads. In: Voigt CCV \& Kingston T (eds.) Bats in the Anthropocene: Conservation of Bats in a Changing World: Springer Science+ Business Media.

[37] Kerth G., Melber M. 2009. Species-Specific Barrier Effects of a Motorway on the Habitat Use of Two Threatened Forest-Living Bat Species. Biological Conservation, 142 (82): 270-279.

[38] Lesiński G. 2007. Bat Road Casualties and Factors Determining Their Number. Mammalia, 71 (3): $138-142$.

[39] Medinas D., Marques J.T., Mira A. 2013. Assessing Road Effects on Bats: The Role of Landscape, Road Features, and Bat Activity on Road-Kills. Ecological Research, 28 (2): 227-237.

[40] Russell A.L., Butchkoski C.M., Saidak L., McCracken G.F. 2009. Road-Killed Bats, Highway Design, and the Commuting Ecology of Bats. Endangered Species Research, 8 (1-2): 49-60.

[41] Berthinussen A., Altringham J. 2012. Do Bat Gantries and Underpasses Help Bats Cross Roads Safely. PloS One, 7 (6): e38775.

[42] Blake D., Hutson A., Racey P., Rydell J., Speakman J. 1994. Use of Lamplit Roads by Foraging Bats in Southern England. Journal of Zoology, 234 (3): 453-462.

[43] Rydell J. 1992. Exploitation of Insects Around Streetlamps by Bats in Sweden. Functional Ecology, 744-750.

[44] Rowse E., Lewanzik D., Stone E., Harris S., Jones G. 2016. Dark Matters: The Effects of Artificial Lighting on Bats. Bats in the Anthropocene: Conservation of Bats in a Changing World. Springer, Cham, 187-213.

[45] Longcore T., Rich C. 2004. Ecological Light Pollution. Frontiers in Ecology and the Environment, 2 (4): 191-198.

[46] Frey J. 1993. Nocturnal Foraging by Scissor-Tailed Flycatchers under Artificial Light. Western Birds, 24 (3): 200.

[47] Arlettaz R., Godat S., Meyer H. 2000. Competition for Food by Expanding Pipistrelle Bat Populations (Pipistrellus pipistrellus) Might Contribute to the Decline of Lesser Horseshoe Bats (Rhinolophus hipposideros). Biological Conservation, 93 (1): 55-60.

[48] Siemers B.M., Schaub A. 2010. Hunting at the Highway: Traffic Noise Reduces Foraging Efficiency in Acoustic Predators. Proceedings of the Royal Society B: Biological Sciences, 278 (1712): 1646-1652.

[49] Bennett V.J., Zurcher A.A. 2013. When Corridors Collide: Road-Related Disturbance in Commuting Bats. The Journal of Wildlife Management, 77 (1): 93-101. 
[50] Fenton M.B. 1997. Science and the Conservation of Bats. Journal of Mammalogy, 78 (1): 1-14.

[51] Ferrara F.J., Leberg P.L. 2005. Influence of Investigator Disturbance and Temporal Variation on Surveys of Bats Roosting under Bridges. Wildlife Society Bulletin, 33 (3): 1113-1122.

[52] Humphrey S.R., Kunz T.H. 1976. Ecology of a Pleistocene Relict, the Western Big-Eared Rat (Plecotus townsendii), in the Southern Great Plains. Journal of Mammalogy, 57 (3): 470-494.

[53] Pearson O.P., Koford M.R., Pearson A.K. 1952. Reproduction of the Lump-Nosed Bat (Corynorhinus rafinesquei) in California. Journal of Mammalogy, 33 (3): 273-320.

[54] Mann S.L., Steidl R.J., Dalton V.M. 2002. Effects of Cave Tours on Breeding Myotis velifer. The Journal of Wildlife Management, 618-624.

[55] Shirley M., Armitage V., Barden T., Gough M., Lurz P., et al. 2001. Assessing the Impact of a Music Festival on the Emergence Behaviour of a Breeding Colony of Daubenton's Bats (Myotis daubentonii). Journal of Zoology, 254 (3): 367-373.

[56] Johnson S.A., Brack V., Rolley R.E. 1998. Overwinter Weight Loss of Indiana Bats (Myotis sodalis) From Hibernacula Subject to Human Visitation. The American Midland Naturalist, 139 (2): 255-262.

[57] Speakman J., Webb P., Racey P. 1991. Effects of Disturbance on the Energy Expenditure of Hibernating Bats. Journal of Applied Ecology, 1087-1104.

[58] Bernstein M., Griffin J., Lempert R. 2006. Impacts on energy expenditures of use. Technical Report Prepared for the Energy Future Coalition, RAND Corporation.

[59] Arnett E.B., Baerwald E.F., Mathews F., Rodrigues L., Rodríguez-Durán A., Rydell J., VillegasPatraca R., Voigt C.C. 2016. Impacts of Wind Energy Development on Bats: A Global Perspective. Bats in the Anthropocene: Conservation of Bats in a Changing World. Springer, Cham, 295-323.

60] Arnett E.B. 2012. Impacts of Wind Energy Development on Wildlife: Challenges and Opportunities for Integrating Science, Management, and Policy. Wildlife Science, CRC Press, 232-257.

61] Arnett E.B., Inkley D.B., Johnson D.H., Larkin R.P., Manes S., Manville A.M., Mason J., Morrison M.L., Strickland M.D., Thresher R. 2007. Impacts of Wind Energy Facilities on Wildlife and Wildlife Habitat. Wildlife Society Technical Review, 7 (2): 49.

[62] Strickland M.D., Arnett E.B., Erickson W.P., Johnson D.H, Johnson G.D., Morrison M.L., Shaffer J.A., Warren-Hicks W. 2011. Comprehensive Guide to Studying Wind Energy/Wildlife Interactions. Prepared for the National Wind Coordinating Collaborative, Washington, DC, USA, 5: 315-324.

[63] Yorulmaz T. 2017. Rüzgar Enerji Santrali ve Yarasalar, http://www.tarkanyorulmaz.com.tr/dosyalar/2, (Erişim Tarihi: 23.12.2019).

[64] Arnett E.B., Erickson P.W., Kerns J., Horn J. 2005. Relationships between Bats and Wind Turbines in Pennsylvania and West Virginia: An Assessment of Fatality Search Protocols, Patterns of Fatality, and Behaviral Interactions with Wind Turbines.

[65] Erickson W., Kronner K., Gritski B. 2003. Nine Canyon Wind Power Project Avian and Bat Monitoring Report.

[66] Ferri V., Locasciulli O., Soccini C., Forlizzi E. 2010. Post Construction Monitoring of Wind Farms: First Records of Direct Impact on Bats in Italy. Hystrix, the Italian Journal of Mammalogy, $22(1)$.

[67] Arnett E.B., Schirmacher M., Huso M.M., Hayes J.P. 2009. Effectiveness of Changing Wind Turbine Cut-in Speed to Reduce Bat Fatalities at Wind Facilities. An Annual Report Submitted to the Bats and Wind Energy Cooperative Bat Conservation International Austin, Texas.

[68] Cole S.G. 2011. Wind Power Compensation is not for the Birds: An Opinion From an Environmental Economist. Restoration Ecology, 19 (2): 147-153.

[69] Kerns J., Kerlinger P. 2004. A Study of Bird and Bat Collision Fatalities at the Mountaineer Wind Energy Center, Tucker County, West Virginia, Annual report for 2003. Prepared for FPL Energy and Mountaineer Wind Energy Center Technical Review Committee.

[70] Baerwald E.F., D'Amours G.H., Klug B.J., Barclay R.M. 2008. Barotrauma is a Significant Cause of Bat Fatalities at Wind Turbines. Current biology, 18 (16): R695-R6.

[71] Furey N.M., Mackie I.J., Racey P.A. 2011. Reproductive Phenology of Bat Assemblages in Vietnamese Karst and its Conservation Implications. Acta Chiropterologica, 13 (2): 341-354. 
[72] Gillieson D. 2009. Caves: processes, development and management. John Wiley \& Sons.

[73] Luo J., Jiang T., Lu G., Wang L., Wang J., Feng I. 2013. Bat Conservation in China: Should Protection of Subterranean Habitats be a Priority. Oryx, 47 (4): 526-531.

[74] Zhang L., Zhu G., Jones G., Zhang S. 2009. Conservation of Bats in China: Problems and Recommendations. Oryx, 43(2): 179-182.

[75] Mohr C.E. 1972. The Status of Threatened Species of Cave-Dwelling Bats. Bulletin of the National Speleological Society, 34 (2): 33-47.

[76] Paksuz S., Özkan B. 2012. The Protection of the Bat Community in the Dupnisa Cave System, Turkey, Following Opening for Tourism. Oryx, 46 (1): 130-136.

[77] Furman A., Özgül A. 2004. The Distribution of Cave-Dwelling Bats and Conservation Status of Underground Habitats in Northwestern Turkey. Biological Conservation, 120 (2): 243-248.

[78] Furman A., Çoraman E., Bilgin R. 2012. Bats and Tourism: A Response to Paksuz \& Özkan. Oryx, 46 (3): 330.

[79] Yorulmaz T. 2010. Güneydoğu Türkiye Yarasaları. Doktora Tezi, Kırıkkale Üniversitesi, Fen Bilimleri Enstitüsü, Kırıkkale.

[80] Deharveng L., Bedos A. 2012. Diversity Patterns in theTropics. Encyclopedia of Caves: Elsevier, 238-250.

[81] Racey P.A., Entwistle A.C. 2000. Life-history and Reproductive Strategies of Bats. Reproductive biology of bats: Elsevier, 363-414.

[82] McCracken G.F. 2011. Cave Conservation: Special Problems of Bats. Course Booklet, 68.

[83] Arslan A., Baş M. 2020. Yarasa Gübresi (Guano). Bitlis Eren Üniversitesi Fen Bilimleri Dergisi, 9 (1): 478-486.

[84] Jung K., Kalko E.K. 2011. Adaptability and Vulnerability of High Flying Neotropical Aerial Insectivorous Bats to Urbanization. Diversity and Distributions, 17 (2): 262-274.

[85] Van der Ree R., McCarthy M.A., 2005. Inferring Persistence of Indigenous Mammals in Response to Urbanisation. Animal Conservation Forum, Cambridge University Press.

[86] Gaisler J., Zukal J., Rehak Z., Homolka M. 1998. Habitat Preference and Flight Activity of Bats in a City. Journal of Zoology, 244 (3): 439-445.

[87] Kurta A., Teramino J.A. 1992. Bat Community Structure in an Urban Park. Ecography, 15 (3): 257-261.

[88] Legakis A., Papadimitriou C., Gaethlich M., Lazaris D. 2000. Survey of the Bats of the Athens Metropolitan Area. Myotis, 38: 41-46.

[89] Lesinski G., Fuszara E., Kowalski M. 2000. Foraging Areas and Relative Density of Bats (Chiroptera) in Differently Human Transformed Landscapes. Zeitschrift fur Saugetierkunde, 65 (3): 129-137.

[90] Walsh A.L., Harris S. 1996. Factors Determining the Abundance of Vespertilionid Bats in Britain: Geographical, Land Class and Local Habitat Relationships. Journal of Applied Ecology, 519-529.

[91] McKinney M.L. 2002. Urbanization, Biodiversity, and Conservation: The Impacts Of Urbanization on Native Species are Poorly Studied, But Educating a Highly Urbanized Human Population About These Impacts can Greatly Improve Species Conservation in all Ecosystems. Bioscience, 52 (10): 883-890.

[92] Coleman J.L., Barclay R.M. 2011. Influence of Urbanization on Demography of Little Brown Bats (Myotis lucifugus) in the Prairies of North America. PLoS One. 6 (5): e20483.

[93] Duchamp J.E., Swihart R.K. 2008. Shifts in Bat Community Structure Related to Evolved Traits and Features of Human-Altered Landscapes. Landscape Ecology, 23 (87): 849-860.

[94] Jung K., Threlfall C.G. 2016. Urbanisation and its Effects on Bats -A Global Meta-Analysis. Bats in the Anthropocene: Conservation of Bats in a Changing World. Springer, Cham, 13-33.

[95] Lumsden L. 2009. The Extinction of the Christmas Island Pipistrelle. Australian Bat Society Newsletter, 33: 21-25.

[96] Martin T.G., Nally S., Burbidge A.A., Arnall S., Garnett S.T., Hayward M.W., Lumsden L.F., Menkhorst P., McDonald-Madden E., Possingham H.P. 2012. Acting Fast Helps Avoid Extinction. Conservation Letters, 5 (4): 274-280.

[97] IUCN. 2019. IUCN Red List of Threatened Species. 2019-3, https://www.iucnredlist.org/ (Erişim Tarihi: 24.12.2019). 